\title{
Subset-Specific Co-stimulatory Signals Are Required for IL-2 Production but Not Growth Inhibition Responses by T Cell Hybrids Specific for Myelin Basic Protein ${ }^{1}$
}

\author{
M. D. MANNIE*,+,2 AND R. NAIRN* \\ *Department of Microbiology and Immunology, University of Michigan Medical School, Ann Arbor \\ Michigan 48109-0620; and the †Department of Microbiology and Immunology, East Carolina \\ University School of Medicine, Greenville, North Carolina 27858-4354
}

Received August 5, 1991; accepted October 14, 1991

\begin{abstract}
Two distinct types of $T$ cell hybridomas (designated $\mathrm{T}_{\mathrm{HYB}}-1$ and $\mathrm{T}_{\mathrm{HYB}}-2$ ) were derived by fusing BW5147 thymoma cells with encephalitogenic $T$ helper cells from Lewis rats. Both subsets required MHC-restricted presentation of determinants within the 72-86 peptide sequence of myelin basic protein (MBP) as a requisite signal for IL-2 production. Unlike $T_{\mathrm{HYB}^{-1}} 1$ hybrids, however, $\mathrm{T}_{\mathrm{HYB}}$ 2 hybrids required additional accessory cell activities that were mediated by radiosensitive nonadherent (RS-NAdh) splenocytes (SPL). In this study, we describe two observations indicating that RS-NAdh SPL enable MBP-specific responses of $\mathrm{T}_{\mathrm{HYB}}-2$ hybrids by providing subset-specific co-stimulatory signals that act independently of antigen recognition pathways. First, RS-NAdh SPL were required by $T_{\mathrm{HYB}^{-}} 2$ hybrids for MBP-stimulated IL-2 production but were not needed when MBP-specific inhibition of hybrid growth was used as an alternative measure of cellular activation. Second, PMA and ionomycin induccd optimal IL-2 production by both $\mathrm{T}_{\mathrm{HYB}}-1$ hybrids and BW5147 thymoma cells but only stimulated low or marginal levels of IL-2 production by $\mathrm{T}_{\mathrm{HYB}}-2$ hybrids. Together, these observations indicate that RS-NAdh SPL were required for the specific response of IL-2 production regardless of whether the response was stimulated by antigen or by mitogens that bypass initial antigen recognition events. This study thereby provides additional evidence that distinct stimulus-response relationships define two T-helper cell lineages in experimental autoimmune encephalomyelitis. () 1992 Academic Press. Inc.
\end{abstract}

\section{INTRODUCTION}

Autoreactive $\mathrm{T}$ cells that induce $\mathrm{EAE}^{3}$ are widely studied as a means to gain insight into encephalitogenic processes responsible for human demyelinating diseases such as multiple sclerosis (1). In Lewis rats, EAE is mediated by $\mathrm{CD} 4^{+} \mathrm{T}$-helper cells specific for overlapping determinants in the 72-86 region of MBP (2-9). Two subsets of EAE-

\footnotetext{
${ }^{1}$ This investigation was supported by National Institutes of Health Grant AI-19273 and by a postdoctoral fellowship from the National Multiple Sclerosis Society (M.D.M., Grant No. FG758-A-1). Synthetic peptides were prepared with support from the University of Michigan Multipurpose Arthritis Center (NIH Grant 5P 60AR 20557-13).

${ }^{2}$ To whom correspondence and reprint requests should be addressed at Department of Microbiology and Immunology, East Carolina University School of Medicine, Greenville, NC 27858-4354.

${ }^{3}$ Abbreviations: EAE, experimental autoimmune encephalomyelitis; GP, guinea pig; HBSS, Hanks' balanced salt solution; mAb, monoclonal antibody; MBP, myelin basic protein; RS-NAdh, radiosensitivenonadherent; SPL, splenocytes; EAU, experimental autoimmune uveoretinitis;
} 
associated T-helper cells have previously been defined by the observation that separate clonotypic specificities were respectively associated with either of two types of $T$ cell activity $(7,8)$. One subset responded to the $72-86$ peptide sequence of MBP by expressing potent EAE transfer activity even though these $T$ cells did not exhibit any detectable antigen-specific in vitro proliferation. Rather, in vitro proliferation to MBP was mediated by a clonotypically unique subset of $T$ cells that was also specific for determinants within the 72-86 MBP sequence. A similar dichotomy of $T$-helper subsets has been implicated in the uveitogenic response to autoantigens of experimental autoimmune uveoretinitis (EAU) (10-13). Namely, major uveitogenic determinants are closely associated but nevertheless structurally distinct from dominant "proliferative" determinants.

Differences in the encephalitogenic and proliferative activities of these $T$ cell subsets may coexist with subset-specific differences in their requirements for specialized types of accessory cell activities. For example, $T$ cells purified from draining lymph nodes of MBP-sensitized Lewis rats responded synergistically to IL-1 and MBP for optimal expression of EAE adoptive transfer activity (14). Conversely, T cells mediating in vitro proliferation to MBP did not exhibit a similar degree of dependence upon IL-1. Additional evidence for subset-specific accessory cell signals was obtained by studying T cell hybrids derived by fusion of murine BW5147 thymoma cells with an encephalitogenic population of MBP-specific T-helper cells (15). Two distinct subsets of hybrids were found that differed in whether RS-NAdh SPL were required for MBPstimulated IL-2 production. Although both subsets required class II MHC-restricted presentation of MBP by adherent APC, $\mathrm{T}_{\mathrm{HYB}}-2$ hybrids also required an additional activity of RS-NAdh SPL that was not required by $T_{\text {HYB }}-1$ hybrids.

The purpose of this study was to test two alternative hypotheses concerning how RS-NAdh SPL enabled $\mathrm{T}_{\mathrm{HYB}}-2$ responses to MBP. The first hypothesis predicts that RS-NAdh SPL may provide requisite co-stimulatory signals to $\mathrm{T}_{\mathrm{HYB}^{-}}-2$ hybrids. Costimulatory signals act in synergy with physically separate signals from MHC-restricted antigens to elicit $T$ cell responses $(16,17)$. Previous studies have shown that $T$ cell clones may have stringent requirements for co-stimulation to mediate certain types of responses and exhibit little or no co-stimulatory requirements for other types of responses. For example, IL-1 is a co-stimulus for antigen-stimulated proliferation of murine Th2 type T cells (18-20). Nevertheless, IL-1 has much less of an effect upon antigen-induced IL-4 production by the same T cells (21). Likewise, disruption of costimulatory molecules by chemical fixation of accessory cells engenders a specific $T$ cell deficit in antigen-stimulated IL-2 production that only partially affects other antigen-dependent responses such as IL-3 and $\gamma$-IFN production (22). Thus, specialized types of co-stimulatory molecules appear to selectively enable specific activities of particular subsets of $\mathrm{T}$ cells.

The second hypothesis predicts that RS-NAdh SPL may promote IL-2 production by enhancing antigen recognition in $\mathrm{T}_{\mathrm{HY}}-2$ hybrids. According to this hypothesis, RS-NAdh SPL may present additional I-A/MBP complexes which are preferentially accessible to $\mathrm{T}_{\mathrm{HYB}}-2$ hybrids. Or perhaps RS-NAdh SPL possess adhesive properties that promote cluster formation involving both $\mathrm{T}_{\mathrm{HYB}}-2$ hybrids and antigen-bearing APC. Any mechanism promoting apposition of $\mathrm{T}_{\mathrm{HYB}^{-}}-2$ hybrids and APC may dramatically potentiate antigen recognition by $\mathrm{T}_{\mathrm{HYB}}-2$ hybrids. Unlike the first hypothesis, the second hypothesis predicts that accessory cell activities that enable antigen rec- 
ognition would also promote other measures of $\mathrm{T}$ cell activation in proportion to that of IL-2 production.

An alternative to the IL -2 production response that can be readily studied in $\mathrm{T}$ cell hybrids involves antigen-induced growth inhibition $(23,24)$. Because $T$ cell hybrids retain the immature characteristics of their thymoma fusion partner, antigenic activation results in a cell cycle block and subsequently results in cell death. Antigeninduced cell death of $T$ cell hybrids is believed to represent mechanisms of clonal deletion by which autoreactive thymocytes are deleted upon recognition of self peptides in the thymus. In this study, antigen-induced growth inhibition was chosen as an alternative assay for cellular activation because it was considered unlikely that a response unique to the murine fusion parent would be regulated by rat co-stimulatory molecules.

The results of this study indicate that RS-NAdh accessory cells enable antigenevoked IL-2 production by $\mathrm{T}_{\mathrm{HYB}}-2$ hybrids through provision of essential co-stimulation. These co-stimulatory signals were delivered independently of $T$ cell antigen receptor transduction of antigen/MHC signals and appeared necessary for both antigenic and mitogenic stimulation of IL-2 production. These findings provide additional cvidence that distinct co-stimulatory requirements define parallel $\mathrm{T}$ cell response pathways in EAE.

\section{MATERIALS AND METHODS}

Rats. Lewis rats were obtained from Harlan-Sprague-Dawley (Indianapolis, IN). These rats were bred in our animal facility and were 5 to 10 weeks old when used in experiments.

Reagents. Guinea pig (GP) MBP was purified from spinal cords (Pel-Freez, Rogers, AR) by standard procedures (25). Two synthetic peptides,

\section{GP72-86: Y G S L P Q K S Q R S Q D E N P V [P $\left.{ }^{80}\right]$ GP72-86: Y G S L P Q K S Q R P Q D E N P V,}

were synthesized and purified by the Biomedical Research Core Facilities at the University of Michigan. Ionomycin was purchased from Calbiochem and PMA was obtained from Sigma. The OX6 B cell hybridoma line that produces anti-rat I-A monoclonal antibody (mAb) (26) was a generous gift of Dr. Alan Williams (University of Oxford, Oxford, England).

$T$ cell hybridomas. As described previously (27), T cell hybrids were derived by fusing MBP-specific T cells from Lewis rats with cells from the BW5147 murine thymoma. T cell hybrids were passaged every 4 days in RPMI- 1640 medium supplemented with $10 \%$ heat-inactivated fetal bovine serum (Hyclone), $2 \mathrm{~m} M$ glutamine (GIBCO), $100 \mu \mathrm{g} / \mathrm{ml}$ streptomycin (GIBCO), $100 \mathrm{U} / \mathrm{ml}$ penicillin (GIBCO), and $50 \mu M$ 2-mercaptoethanol (Sigma).

$T$ cell hybrid responses to MBP as measured by $I L-2$ production and growth inhibition. T cell hybrids $\left(2.5-10 \times 10^{4}\right.$ cells/well $)$ were cultured with $5 \times 10^{5} \mathrm{SPL}$ with or without antigen in 96-well microtiter plates. After $18 \mathrm{hr}$, the cultures were pulsed for an additional $6 \mathrm{hr}$ with $1 \mu \mathrm{Ci}$ of $\left[{ }^{3} \mathrm{H}\right]$ thymidine $(6.7 \mathrm{Ci} / \mathrm{mmole}, \mathrm{NEN})$. The supernatants $(100 \mu \mathrm{l} /$ well) were transferred into replicate plates and the hybrids were then harvested on fiberglass filters to measure $\left[{ }^{3} \mathrm{H}\right]$ thymidine incorporation. As described by Mosmann (28), IL-2 production was measured in a bioassay in which the 
tetrazolium salt MTT (Sigma) was used to measure viability and growth of the IL-2dependent CTLL cell line. Briefly, CTLL cells $\left(5 \times 10^{4} / 50 \mu \mathrm{l} /\right.$ well $)$ were cultured for $18 \mathrm{hr}$ with supernatants from T cell hybridoma cultures. Then, $20 \mu \mathrm{l}(5 \mathrm{mg} / \mathrm{ml})$ of MTT was added to each well. Four hours later, $120 \mu \mathrm{l}$ of medium was discarded from each well and $100 \mu \mathrm{l}$ of $0.04 \mathrm{~N} \mathrm{HCl}$ in isopropanol (Baker) was added to dissolve the dark blue crystals of the MTT formazan product. The 96-well plates were then read at $570 \mathrm{~nm}$ on an ELISA reader (Microplate Reader, Bio-Rad). By this procedure, IL2 production and growth inhibition were measured in the same single well cultures.

Preparation of splenic accessory cells. SPL were obtained from untreated Lewis rats and were washed twice in Hanks' balanced salt solution (HBSS). Then, designated aliquots of SPL were exposed to a source of $\gamma$-irradiation (1500 or 3000 rads, MARK IV irradiator). To obtain the adherent fraction, SPL were aliquoted into 96 -well plates and incubated in culture medium for $2 \mathrm{hr}$. Nonadherent SPL were removed by vigorously washing the plates three times with HBSS. Adherent cells remained firmly attached to the bottom of the wells and were judged to be macrophages by phase contrast microscopy.

\section{RESULTS AND DISCUSSION}

Two subsets of MBP-specific hybrids defined by different accessory cell requirements. Previous research (15) has shown that the $T_{H Y B}-2$ and $T_{H Y B}-1$ subsets are respectively represented by the LSS-C1 and LSS-D1 hybrids. As shown in Fig. 1, the $\mathrm{T}_{\text {HYB }}-2$ hybrid was distinguished from the $T_{\text {HYB }}-1$ hybrid by its requirement for a unique type of accessory cell activity (bottom panel). This accessory cell activity was greatly diminished by pretreatment of SPL with $\gamma$-irradiation ( 3000 rads) and was virtually eliminated by removal of the nonadherent cell fraction (bottom panel). The loss of this accessory cell activity did not involve a deficit in antigen presentation because the $T_{\mathrm{HYB}^{-1}} 1$ hybrid responded similarly to GPMBP when cultured with either SPL, irradiated SPL, or irradiated adherent SPL (top panel). Nor was it likely that this loss of accessory cell activity reflected limiting IL-1 production, because cell types that produce IL-1 (adherent macrophages) were not depleted from these cultures. In the same experiment, two other $\mathrm{T}_{\mathrm{HYB}}-1$ hybrids and four other $\mathrm{T}_{\mathrm{HYB}}-2$ hybrids exhibited the distinctive response profiles of the LSS-D1 and LSS-C1 hybrids, respectively. This experiment revealed that accessory cell activities of RS-NAdh SPL arc optimally mcasurcd by comparing the activity of normal SPL with that of irradiated adherent SPL.

Growth inhibition of $T$ cell hybridomas. Like mouse-mouse $T$ cell hybrids, these rat-mouse $\mathrm{T}$ cell hybrids also exhibited growth inhibition when exposed to GPMBP (Fig. 2). The spontaneous proliferation by 11 hybrids was inhibited upon presentation of GPMBP by splenic APC (Fig. 2 legend). Furthermore, inhibition of hybrid growth was proportional to the stimulation of IL-2 production. To test whether GPMBP nonspecifically inhibited hybrid proliferation, similar experiments were also performed with synthetic peptide GP72-86 which represents amino acid residues 72-86 of the encephalitogenic GPMBP sequence (Fig. 3). This peptide also inhibited hybrid growth at concentrations that induced proportional levels of IL- 2 production. Neither GPMBP nor GP72-86 inhibited proliferation of BW5147 cells or of T cell hybrids cultured in the absence of splenic APCs (M. D. Mannie, unpublished observations).

Two additional types of experiments were performed to assess whether IL-2 production and growth inhibition represented responses evoked by the same antigen 

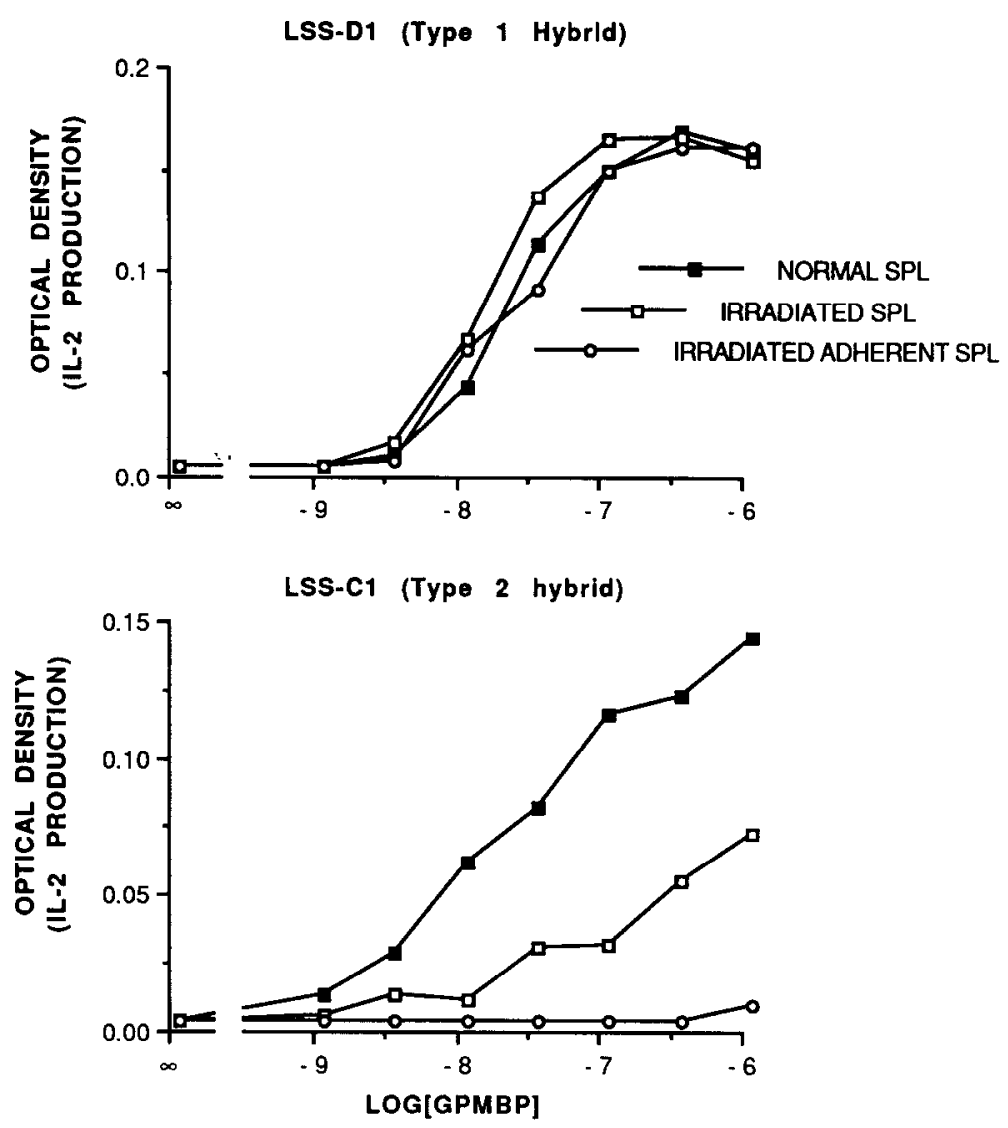

FIG. 1. The $T_{\mathrm{HYB}^{-1}}$ and $\mathrm{T}_{\mathrm{HYB}^{-}}-2$ subsets of $\mathrm{T}$ cell hybrids have different requirements for RS-NAdh SPL. The LSS-D1 and LSS-C1 hybrids are representative of the $T_{\mathrm{HYB}^{-1}}$ and $T_{\mathrm{HYB}^{-}} 2$ subsets, respectively. These hybrids $\left(10^{5} /\right.$ well) were cultured for $24 \mathrm{hr}$ with different concentrations of GPMBP and either SPL $(5 \times$ $10^{5} /$ well), irradiated SPL (3000 rads, $5 \times 10^{5} /$ well), or irradiated adherent SPL. Supernatants were then transferred to replicate plates, and II,-2 activity was measured by the MTT assay of CTLL viability. These results represent three experiments.

recognition events. First, a mAb specific for rat I-A molecules (OX6) was used to block $\mathrm{T}$ cell responses to GPMBP. This mAb specifically reversed GPMBP-induced growth inhibition as measured by a concentration-dependent enhancement of hybrid proliferation but did not affect the growth of hybrids cultured in the absence of GPMBP (left two panels of Fig. 4). Thus, OX6 specifically reversed GPMBP-induced growth inhibition. The concentration dependence of this blockade was similar to that for GPMBP-induced IL-2 production (two right panels of Fig. 4). These results indicate that same type of MIIC-restricted antigen recognition event induces both growth inhibition and IL-2 production.

Second, antigenic competition experiments were performed to assess whether competitive inhibition of antigen recognition would reverse growth inhibition as well as IL-2 production (Fig. 5). The LSS-A1 hybrid exhibited potent reactivity to GP72-86 but did not respond to $\left[\mathbf{P}^{80}\right]$ GP72-86 even though the two peptides differ only by a single proline $\mathrm{e}^{80}$ for serine $\mathrm{e}^{80}$ substitution. Rather, $\left[\mathrm{P}^{80}\right]$ GP72-86 competitively inhibited 

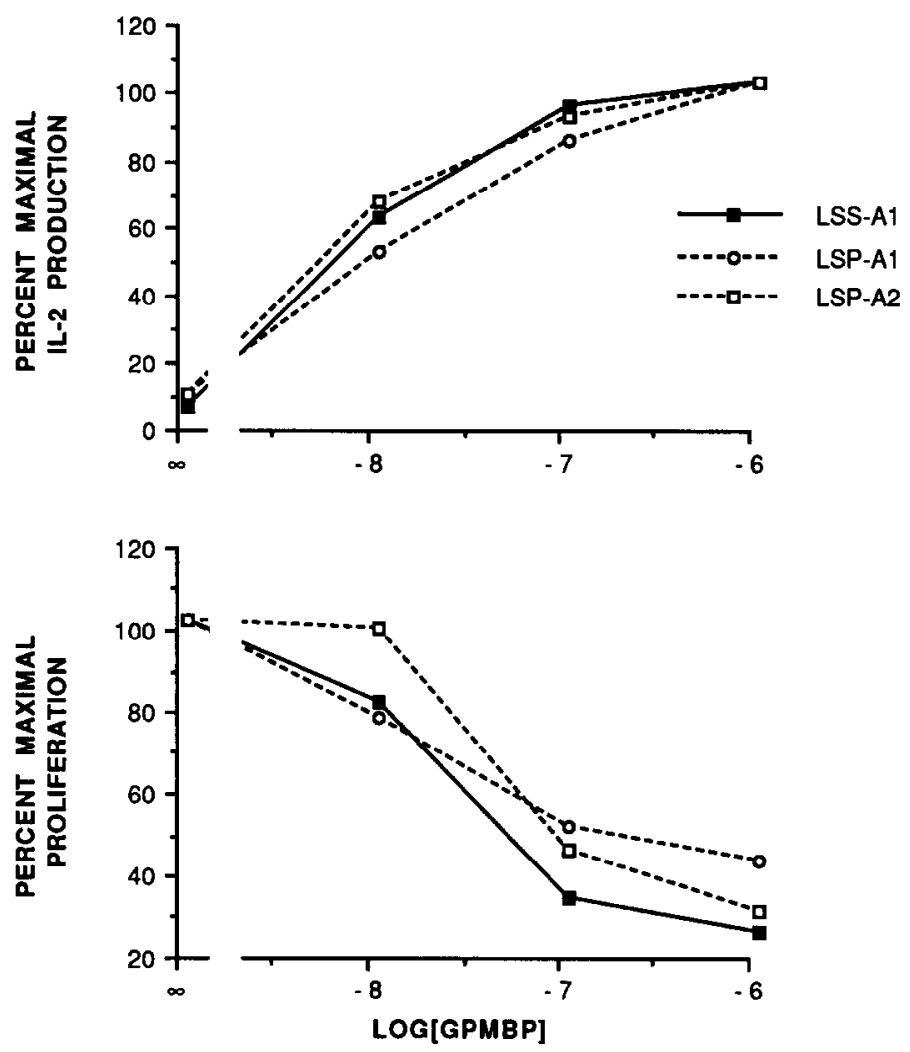

FIG. 2. GPMBP inhibits spontaneous proliferation of $T$ cell hybrids and proportionally stimulates IL-2 production. T cell hybrids $\left(2.5 \times 10^{4} /\right.$ well) were cultured with SPL $\left(5 \times 10^{5} /\right.$ well $)$ and with different concentrations of GPMBP. These cultures were pulsed with $1 \mu \mathrm{Ci}$ of $\left[{ }^{3} \mathrm{H}\right]$ thymidine during the last $6 \mathrm{hr}$ of a 24-hr culture. The supernatants were transferred to replicate plates, and the hybrids were then harvested on fiberglass filters to measure $\left[{ }^{3} \mathrm{H}\right]$ thymidine incorporation by scintillation counting. The supernatants were assayed for IL-2 activity by the MTT assay of CTLL viability (see Materials and Methods). Solid lines and dashed lines respectively represent responses of $T_{\mathrm{HYB}}-1$ and $\mathrm{T}_{\mathrm{HYB}}-2$ hybrids. Eleven hybrids were assayed in this experiment even though the results from only three are presented. The percentage of antigen-specific growth inhibition as well as the corresponding production of IL-2 (as measured by OD units from the MTT assay) for each hybrid was LSP-A1, 59\% (0.633); LSP-A2, 73\% (0.658); LAS-A1, 55\% (0.643); LSS-A1, 76\% (0.673); LSS-B2, 62\% (0.720); LSS-B3, 53\% (0.545); LSS-C1, 55\% (0.456); LSS-C2, 56\% (0.662); LSS-D1, $43 \%(0.711)$; LSS-D2, 65\% (0.347), and LSS-D3, 87\% (0.470). These results represent four experiments.

recognition of GP72-86 by LSS-A1 hybrids. Other studies (29) have shown that the mechanism of inhibition may involve competitive interactions for peptide binding sites on I-A molecules. As shown in Fig. 5, concentrations of $\left[\mathrm{P}^{80}\right] \mathrm{GP72}-86$ that competitively blocked IL-2 production also blocked the response of growth inhibition in a proportional manner. These results provide additional evidence that both types of response are elicited by the same type of antigen recognition event.

Co-stimulatory signals are required for $I L-2$ production but not growth inhibition of $T_{H Y B}-2$ hybrids. To assess how accessory cells promoted $\mathrm{T}_{\mathrm{HYB}^{-}}-2$ responses to $\mathrm{MBP}$, IL-2 production and growth inhibition were assayed in the presence or in the absence of RS-NAdh SPL (Table 1). Hybrids cultured with nonfractionated SPL responded to GPMBP by producing IL-2 while also exhibiting growth inhibition. Both hybrid 

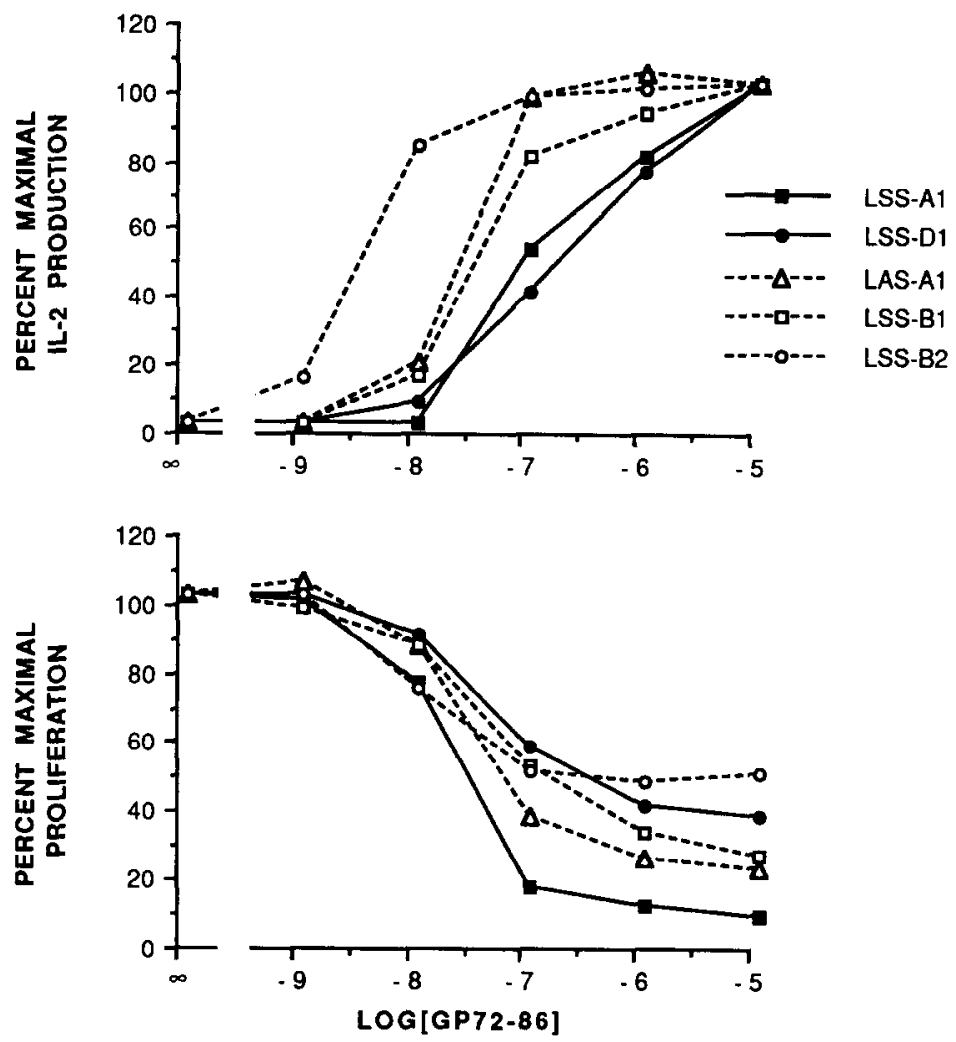

FIG. 3. The encephalitogenic peptide GP72-86 also inhibits hybrid growth and proportionally stimulates IL-2 production. As described in the legend of Fig. 2, five hybrids were cultured with SPL and with different concentrations of GP72-86. Hybrid growth was measured by $\left[{ }^{3} \mathrm{H}\right]$ thymidine incorporation and IL-2 production was measured by the MTT assay of CTLL viability. Solid lines and dashed lines respectively represent responses of $T_{\mathrm{HYB}^{-1}}$ and $\mathrm{T}_{\mathrm{HYB}}-2$ hybrids. These results represent two experiments.

subsets also exhibited GPMBP-specific growth inhibition when cultured with irradiated adherent SPL. In the latter cultures however, GPMBP exclusively stimulated IL-2 production by $T_{H Y B}-1$ hybrids but not by $T_{H Y B}-2$ hybrids. Thus, responses of IL-2 production and growth inhibition by the same clone in the same culture were dissociated based upon differential accessory cell requirements.

Nor did the dissociation of growth inhibition from IL-2 production reflect a small quantitative difference within a narrow set of experimental conditions. Rather, this dissociation was observed across a wide range of adherent cell densities (Fig. 6) and GPMBP concentrations (Fig. 7). The interpretation most consistent with these data is that RS-NAdh SPL provide co-stimulatory signals necessary for MBP-induced IL2 production by $\mathrm{T}_{\mathrm{HYB}}-2 \mathrm{~T}$ cell hybrids.

The differential co-stimulatory requirements of $T_{\mathrm{HYB}^{-}}-1$ and $T_{\mathrm{HYB}}-2$ hybrids did not correlate with any consistent quantitative difference in response parameters such as the potency or magnitude of the IL-2 response that could be detected in the presence of nonfractionated SPL (27). Nor did the requirement for co-stimulation correlate with differential expression of rat CD2, CD4, CD8, CD45, Thy-1, or IL-2 receptor proteins by T cell hybrids (M. D. Mannie, unpublished observations). Rather, these 

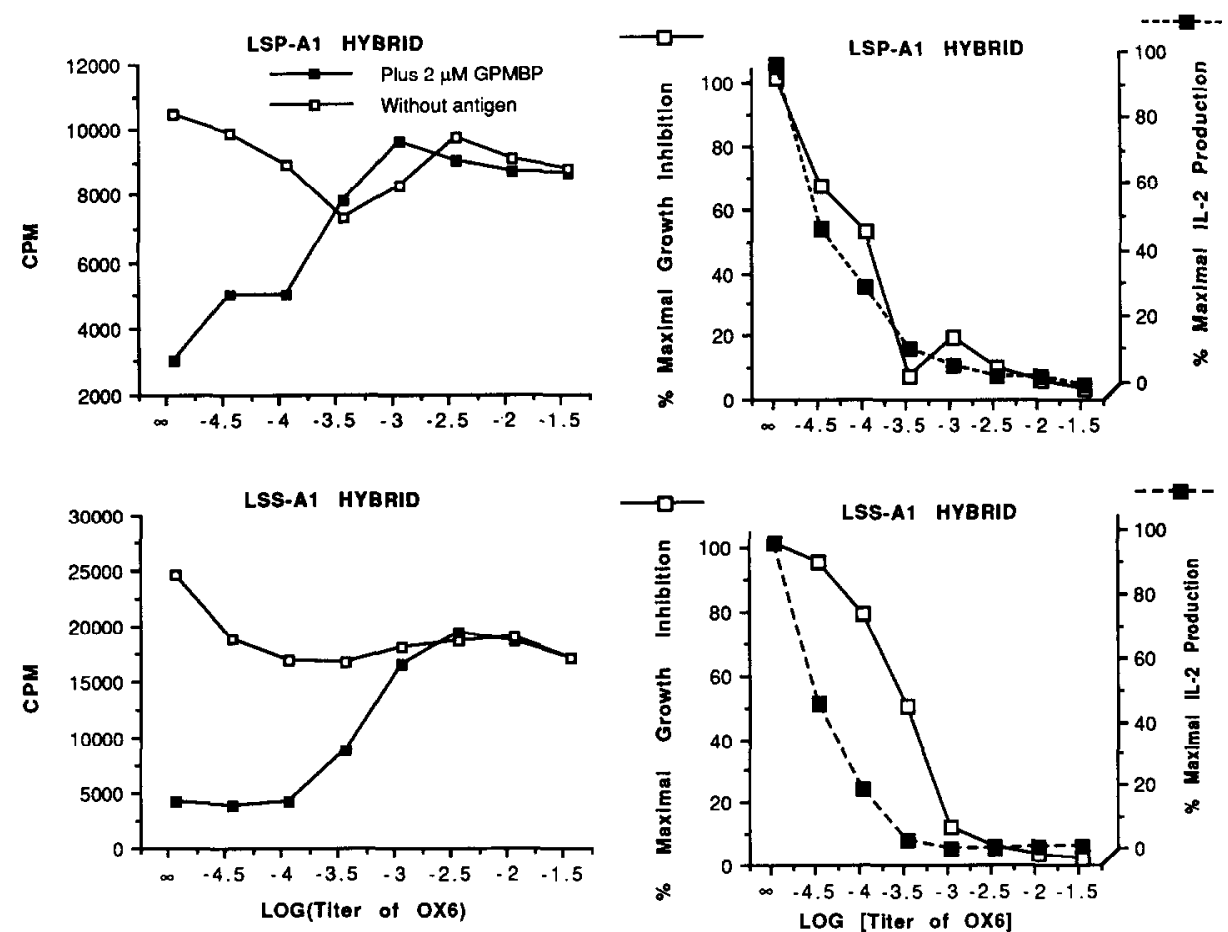

FIG. 4. Concentrations of anti-rat I-A mAb that block GPMBP-specific growth inhibition are similar to those that block GPMBP-stimulated IL-2 production. Designated hybrids and SPL were cultured with different concentrations of the OX6 mAb for $1 \mathrm{hr}$, and then $2 \mu M$ GPMBP was added to designated wells. Hybrid proliferation and IL-2 production were measured as described under Materials and Methods. These results represent four experiments.

subset-specific differences in co-stimulatory requirements are attributed to qualitative differences in the molecular physiology of $\mathrm{T}$ cell activation pathways leading to IL-2 production.

However, additional experiments were needed to establish that these subset-specific differences reflected differential co-stimulatory requirements rather than differential production of co-stimulatory molecules. According to the latter possibility, both subsets may share the same requirements for co-stimulation with the subset-specific differences instead reflecting autologous production of co-stimulatory molecules by $T_{\mathrm{HYB}}-1$ hybrids but not by $\mathrm{T}_{\mathrm{HYB}}-2$ hybrids. If so, then $\mathrm{T}_{\mathrm{HYB}}-1$ hybrids would provide co-stimulatory signals that would fulfill the activation requirements of $\mathrm{T}_{\mathrm{HYB}}-2$ hybrids. To test this possibility, a $T_{\mathrm{HYB}^{-1}}$ hybrid (LSS-D1) and a $\mathrm{T}_{\mathrm{HYB}}-2$ hybrid (LSP-A1) were co-cultured together with irradiated adherent APCs and the peptide $\left[\mathrm{P}^{80}\right]$ GP72-86 (Table 2). This antigen specifically stimulates the $T_{\mathrm{HYB}}-2$ hybrid but is not recognized by the $T_{\mathrm{HYB}^{-1}}$ hybrid. Under these experimental conditions, the $T_{\mathrm{HYB}}-2$ will not produce IL-2 due to the lack of a co-stimulus unless the co-stimulus is provided by the $\mathrm{T}_{\mathrm{HYB}}-1$ hybrid. As shown in Table 2, the $T_{\mathrm{HYB}^{-}}-2$ hybrid responded to $\left[\mathrm{P}^{80}\right]$ GP72-86 when cultured with SPL but not when cultured with irradiated adherent APCs. Furthermore, the addition of $\mathrm{T}_{\mathrm{HYB}^{-}}-1$ hybrids to these cultures did not reconstitute the co-stimulatory signal. These results provide further evidence that the two subsets differ in their requirements for co-stimulation. 


\section{IL-2 PRODUCTION}
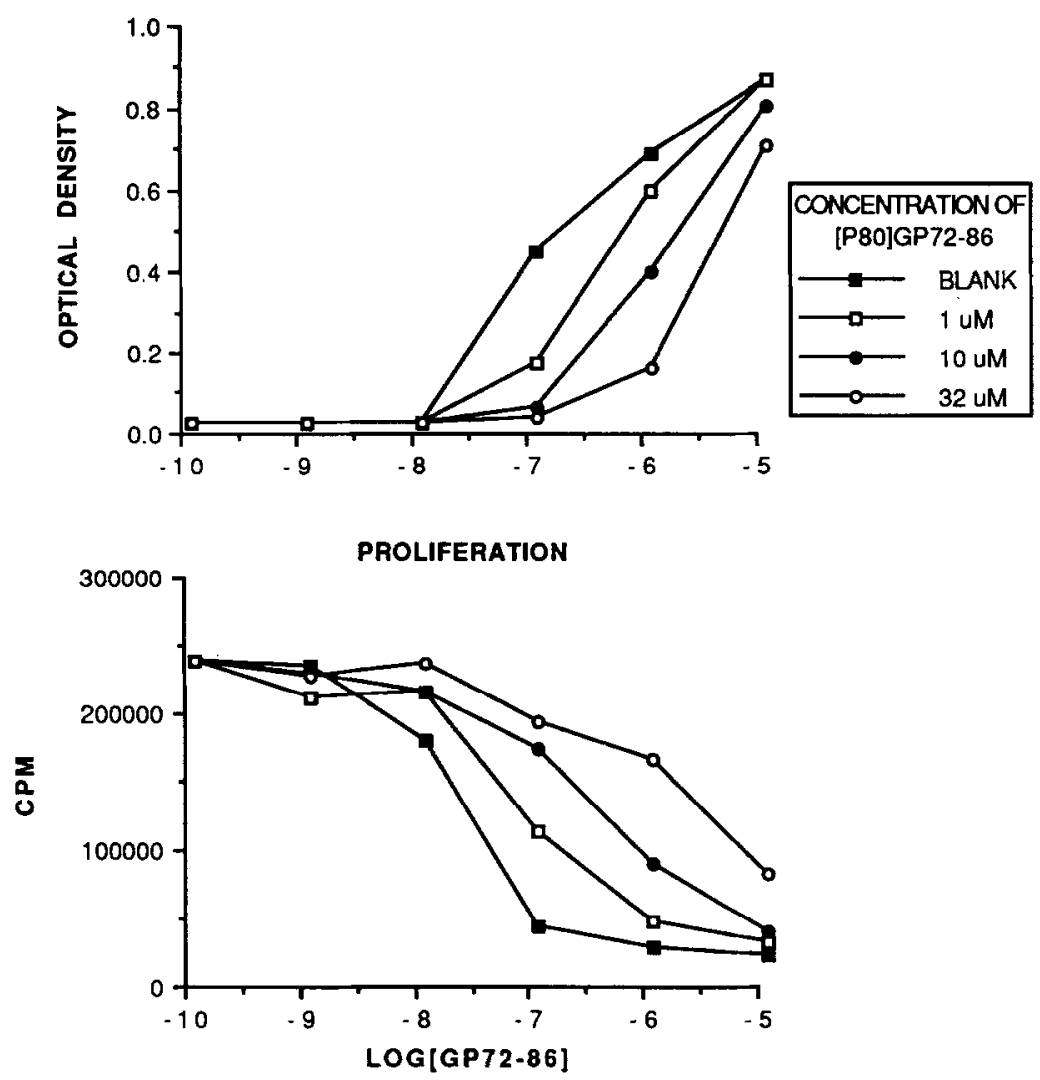

FIG. 5. $\left[\mathrm{P}^{80}\right] \mathrm{GP} 72-86$ competitively inhibits GP72-86-stimulated IL-2 production and concomitantly reverses GP72-86-induced growth inhibition. Antigenic competition was used as a means to determine whether the hybrid responses of IL-2 production and growth inhibition were dependent upon the same antigen recognition events. The LSS-A I hybrid $\left(5 \times 10^{4} /\right.$ well $)$ was cultured with SPL $\left(5 \times 10^{5} /\right.$ well $)$ and different concentrations of GP72-86 in the presence of either $0,1,10$, or $32 \mu M$ of [P $\left.{ }^{8 n}\right]$ GP72-86 for 24 hrs. Hybrid growth inhibition and IL-2 production were respectively measured by $\left[{ }^{3} \mathrm{H}\right]$ thymidine incorporation and by the MTT assay of CTLL viability. In the same experiment, similar results were obtained for the LSS-DI hybrid. These results represent three experiments.

Mitogenic responsiveness of $T_{H Y B}-1$ and $T_{H Y B^{-}} 2$ subsets. The studies described above showed that the pathway leading to IL-2 production in $\mathrm{T}_{\mathrm{HYB}^{-}}-1$ hybrids differs from that in $\mathrm{T}_{\mathrm{HYB}}-2$ hybrids. However, the molecular nature of this difference has yet to be defined. To gain insight into this question, we hypothesized that regulatory mechanisms selectively expressed within $\mathrm{T}_{\mathrm{HYB}}-2$ hybrids may act to repress a pivotal intracellular mediator in the cascade of intracellular events leading to IL-2 production. To address this question, $\mathrm{T}_{\mathrm{HYB}}-2$ hybrids were cultured with PMA and ionomycin to determine whether mitogenic signals as opposed to antigenic signals would suffice to elicit IL-2 production in the absence of co-stimulation. The mitogenic combination of PMA and ionomycin was chosen for these studies because these compounds are known to respectively elicit protein kinase $\mathrm{C}$ activation and $\mathrm{Ca}^{2+}$ influx. These events synergistically induce cellular activation and lymphokine production (30). PMA and ionomycin are 
TABLE 1

$\mathrm{T}_{\mathrm{HYB}}$-2-Specific Co-stimulatory Factors Required for GPMBP-Stimulated IL-2 Production Are Not Required for GPMBP-Induced Growth Inhibition

\begin{tabular}{|c|c|c|c|}
\hline \multirow[b]{2}{*}{$\begin{array}{l}\text { Hybrid [and subset] } \\
\text { designation }^{b}\end{array}$} & \multicolumn{2}{|c|}{ Percent maximal growth inhibition: ${ }^{a}$} & \multirow[b]{2}{*}{ Maximal IL-2 production } \\
\hline & $\begin{array}{l}\text { In culture } \\
\text { with SPL }\end{array}$ & $\begin{array}{l}\text { In culture with } \\
\text { IRRADH }\end{array}$ & \\
\hline LSS-A1 [1] & $64 \%$ & $79 \%$ & $61 \%$ \\
\hline LSS-D1 [1] & $47 \%$ & $76 \%$ & $92 \%$ \\
\hline LSP-A1 [2] & $52 \%$ & $51 \%$ & $2 \%$ \\
\hline LSP-A2 [2] & $63 \%$ & $61 \%$ & $5 \%$ \\
\hline LAS-A1 [2] & $55 \%$ & $56 \%$ & $9 \%$ \\
\hline LSS-C1 [2] & $55 \%$ & $60 \%$ & $1 \%$ \\
\hline
\end{tabular}

${ }^{a}$ Hybrids were cultured with either SPL or irradiated adherent SPL (IRRADH) in the presence or absence of GPMBP for $24 \mathrm{hr}$. [ $\left.{ }^{3} \mathrm{H}\right]$ thymidine incorporation and IL-2 production were measured as described under Materials and Methods. GPMBP-induced percent inhibition of hybrid growth was defined as 1 minus the ratio of mean cpm from triplicate wells with $1 \mu M$ GPMBP to mean cpm of triplicate wells without GPMBP.

${ }^{b}$ The hybrid designations have been previously described (12). Subset designations [1] and [2] respectively refer to the $\mathrm{T}_{\mathrm{HYB}^{-1}}-1$ and $\mathrm{T}_{\mathrm{HYB}}-2$ subsets.

${ }^{c}$ Percent maximal IL-2 production was defined as mean OD values from triplicate wells with GPMBP/ IRRADH SPL divided by the mean OD values from triplicate wells with GPMBP/SPL. Mean OD values from hybrids and SPL cultured with GPMBP were (from top to bottom): $0.222,0.242,0.159,0.206,0.175$, and 0.138 . Mean $O D$ values obtained from triplicate wells without antigen were subtracted from mean OD values from experimental groups. These results represent three experiments.

also known to elicit IL-2 production by the BW5147 thymoma fusion parent of these hybrids (31). Hence, these mitogens would predictably stimulate IL-2 production only if the IL-2 production pathway was repressed at a point before rather than after activation of protein kinase $\mathrm{C}$ and mobilization of intracellular $\mathrm{Ca}^{2+}$.

As shown in Table 3, $\mathrm{T}_{\mathrm{HYB}}-2$ hybrids exhibited responses to $\mathrm{PMA}$ and ionomycin that were low or negligible as compared either to the respective mitogenic responses of $\mathrm{T}_{\mathrm{HYB}^{-1}} 1$ hybrids or to the antigenic responses (GPMBP $+\mathrm{SPL}$ ) of $\mathrm{T}_{\mathrm{HYB}^{-}}-2$ hybrids. Furthermore, these subset-specific differences in mitogenic activity represented large differences in optimal levels of IL-2 production rather than quantitative differences of sensitivity to different mitogen concentrations (Fig. 8). The $\mathrm{T}_{\mathrm{HYB}}-2$ hybrids also lacked normal mitogenic responsiveness as compared to the BW5147 thymoma parent cell line. In five additional experiments, the response of BW5147 thymoma cells and LSP-A2 hybrids ( $\left.\mathrm{T}_{\mathrm{HYB}}-2\right)$ to PMA and ionomycin respectively averaged 92 and $26 \%$ of the response exhibited by LSS-A1 hybrids $\left(\mathrm{T}_{\mathrm{HYB}}-1\right)$. These experiments also revealed that low levels of apparent IL-2 production by LSP-A2 were attributed to the carryover of PMA and ionomycin which promoted viability and growth of CTLL cells. These latter findings support the possibility that $\mathrm{T}_{\mathrm{HYB}}-2$ hybrids may not produce any IL-2 in response to PMA and ionomycin. Overall, these findings are consistent with the concept that (a) IL-2 production pathways are repressed in $\mathrm{T}_{\mathrm{HYB}}-2$ hybrids and (b) co-stimuli from RS-NAdh SPL act to restore critical events in IL-2 production pathways subsequent to the generation of signals for protein kinase $\mathrm{C}$ activation or $\mathrm{Ca}^{2+}$ influx. 

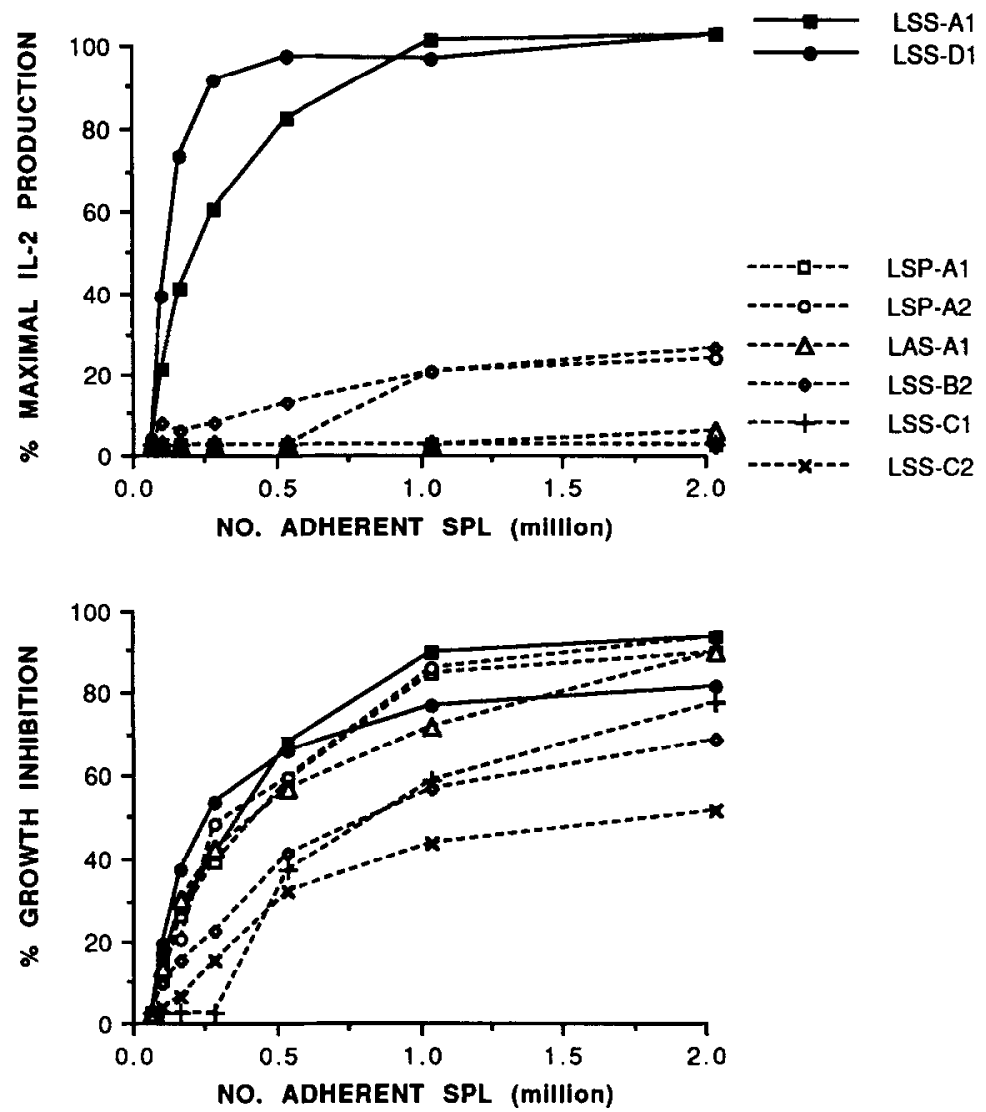

FIG. 6. The dissociation of growth inhibition from IL-2 production was apparent across a wide range of adherent cell densities. Monolayers of irradiated adherent SPL were isolated by incubating irradiated SPL for $2 \mathrm{hr}$ in complete RPMI medium at densities of $2 \times 10^{6}, 1 \times 10^{6}, 5 \times 10^{5}, 2.5 \times 10^{5}, 1.25 \times 10^{5}, 6 \times$ $10^{4}$, or 0 cells/well. Nonadherent cells were removed by washing the wells three times with HBSS. T cell hybrids $\left(2.5 \times 10^{4} /\right.$ well) were added to these wells and were cultured with or without $1 \mu M$ GPMBP. As described under Materials and Methods, the growth inhibition was measured by $\left[{ }^{3} \mathrm{H}\right]$ thymidine incorporation and IL-2 production was measured by the MTT assay of CTLL growth. Percent decrease in $\left[{ }^{3} \mathrm{H}\right]$ thymidine incorporation was defined as 1 minus the ratio of mean cpm from triplicate wells with GPMBP and irradiated adherent SPL to the mean cpm of corresponding triplicate wells with GPMBP but without irradiated adherent SPL. The percentage of maximal IL-2 production was defined as mean OD values from triplicate wells with GPMBP and irradiated adherent SPL divided by the mean OD values from triplicate wells with GPMBP and SPL. Solid lines and dashed lines respectively represent responses of $T_{\mathrm{HYB}^{-1}}$ and $\mathrm{T}_{\mathrm{HYB}}-2$ hybrids. These results represent two experiments.

Co-stimulatory molecules of RS-NAdh SPL are distinct from IL-1. Research into the activation requirements of mouse-mouse $T$ cell hybridomas has led to the view that hybrids do not exhibit the co-stimulatory requirements of their normal $T$ cell counterparts $(32,33)$. However, the results presented herein show that rat-mouse $\mathrm{T}$ cell hybridomas can be used to study at least certain types of co-stimulatory signals required by at least one $\mathrm{CD} 4^{+} \mathrm{T}$-helper subset. Hence, whether $\mathrm{T}$ cell hybrids can be used to study co-stimulatory pathways may reflect species variations, the subset of $T$ cell used to derive the hybridomas, and the types of co-stimulatory molecules under study. 

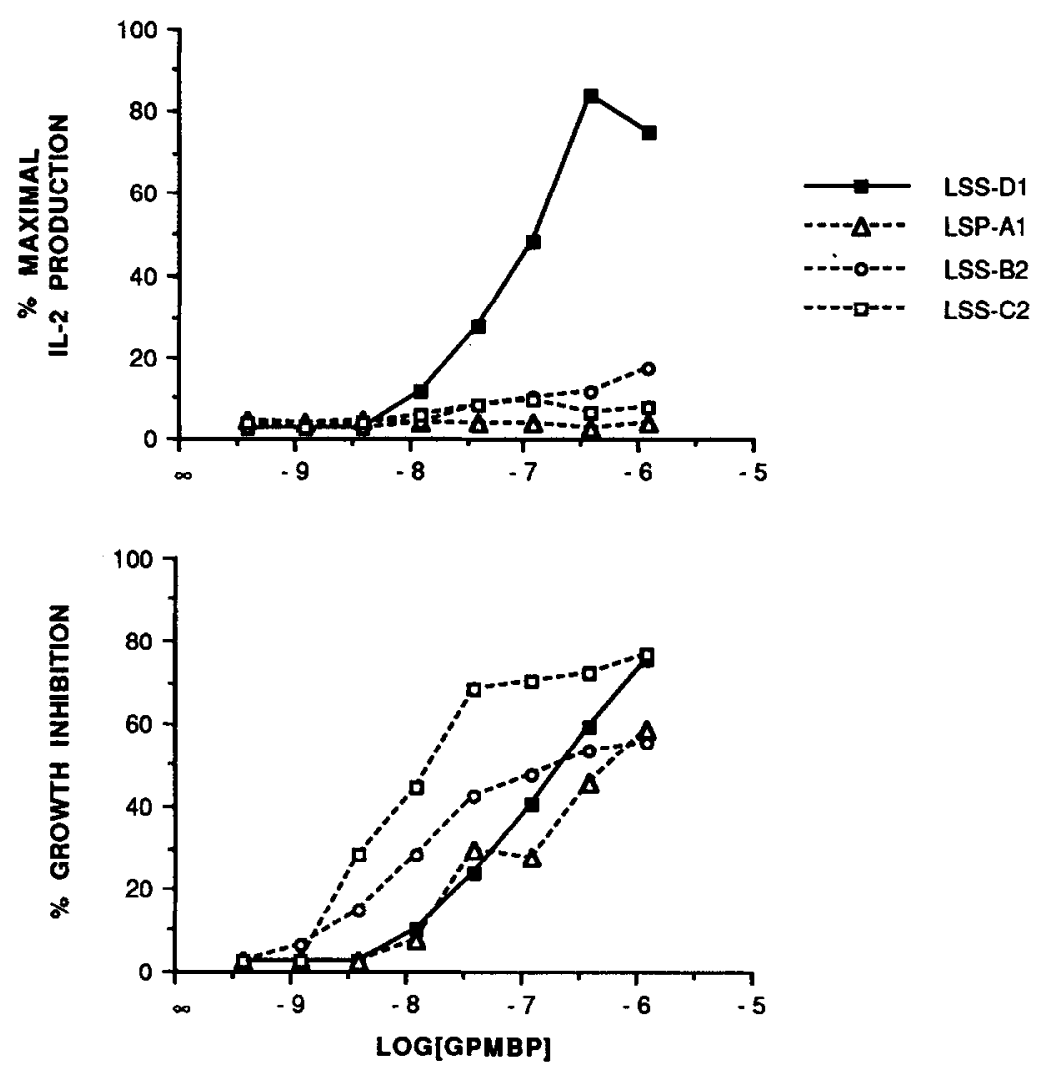

FIG. 7. The dissociation of growth inhibition from IL-2 production was apparent across a wide range of GPMBP concentrations. Irradiated monolayers of adherent SPL were prepared by incubating $2 \times 10^{6}$ irradiated SPL/well for $2 \mathrm{hr}$ in 96-well plates. The nonadherent fraction was then removed by washing three times in HBSS. Adherent SPL and the designated hybrids were cultured with different concentrations of GPMBP for $24 \mathrm{hr}$ to measure growth inhibition and IL-2 production. Percent decrease in [ $\left.{ }^{3} \mathrm{H}\right]$ thymidine incorporation was defined as 1 minus the ratio of mean cpm from triplicate wells with GPMBP to the mean cpm of triplicate wells without GPMBP. The percentage of maximal IL-2 production was defined as mean OD units from triplicate wells with GPMBP and irradiated adherent SPL divided by the mean OD units from triplicate wells with GPMBP and SPL. Solid lines and dashed lines respectively represent responses of $T_{\mathrm{HYB}}-1$ and $\mathrm{T}_{\mathrm{HYB}}-2$ hybrids. These results represent three experiments.

For example, IL-1 has been shown to be an important co-stimulator of encephalitogenic $T$ cells (14). After derivation of the hybrids described in this study, experiments were performed to determine whether the hybrids retained the IL-1 reactivity of their parent MBP-specific T cells. Again, two types of hybrids were found based upon their differential reactivity to IL-1 (Table 4). In the presence of irradiated thymocytes, GPMBP stimulated high levels of IL-2 production by four hybrids and substantially lower levels of IL-2 production by seven other hybrids. The addition of exogenous IL1 had little or no effect upon the former group of hybrids. In the latter group of hybrids, however, exogenous IL-1 acted in concert with GPMBP to promote IL-2 production by six of seven hybrids. This was a paradoxical observation, because $T$ cell dependency on IL-1 is usually observed only when IL-1 producing APC are not included in the culture (14). Possibly, IL-1 was not produced in sufficient concentrations by irradiated 
TABLE 2

$\mathrm{T}_{\mathrm{HYB}^{-1}}$ Hybrids Do Not Provide Co-stimulatory Signals to $\mathrm{T}_{\mathrm{HYB}^{-2}}$ Hybrids $^{a}$

\begin{tabular}{|c|c|c|c|c|}
\hline \multirow{2}{*}{$\begin{array}{l}\text { Accessory } \\
\text { Cells }\end{array}$} & \multicolumn{2}{|c|}{ IL-2 production elicited by } & \multicolumn{2}{|c|}{ (Mean OD values) $^{b}$} \\
\hline & $\mathrm{T}_{\mathrm{HYB}}-2$ hybrid & $\mathrm{T}_{\mathrm{HYB}^{-1}}$ hybrid & GPMBP & {$\left[\mathrm{P}^{80}\right] \mathrm{GP} 72-86$} \\
\hline SPL & LSP-A2 & - & 0.210 & 0.214 \\
\hline IRRADH & LSP-A2 & - & 0.014 & 0.006 \\
\hline IRRADH & - & LSS-D1 & 0.377 & 0.000 \\
\hline IRRADH & I.SP-A2 & ISS-D1 & 0.392 & 0.018 \\
\hline IRRADH & - & LSS-A1 & 0.353 & 0.003 \\
\hline IRRADH & LSP-A2 & LSS-A1 & 0.376 & 0.023 \\
\hline
\end{tabular}

${ }^{a}$ Designated types of accessory cells were cultured with $T_{\mathrm{HYB}^{-}}-2$ hybrid cells, with $\mathrm{T}_{\mathrm{HYB}^{-1}}$ hybrid cells, or with both types of hybrids together. After $24 \mathrm{hr}$ of culture, IL-2 production was measured from each well as described under Materials and Methods. Similar results were also obtained in an additional experiment in which the LSP-A1 hybrid was mixed with either the LSS-A1 hybrid or the LSS-D1 hybrid.

${ }^{b}$ Mean OD values are from triplicate wells with $2 \mu M$ GPMBP or $1 \mu M\left[\mathrm{P}^{80}\right] \mathrm{GP} 72-86$.

thymocytes to optimally stimulate this latter group of hybrids. Alternatively, these hybrids may have lost the capacity to trigger IL-1 production by these APC.

The IL-1 responsive and IL-1 nonresponsive hybrids were subsequently characterized as $\mathrm{T}_{\mathrm{HYB}^{-}}-2$ and $\mathrm{T}_{\mathrm{HYB}^{-}}-1$ subsets based upon their differential requirement for RS-NAdh accessory cells. However, IL-1 responsiveness was lost during long-term in vitro propagation and recloning of the $\mathrm{T}_{\mathrm{HYB}^{-}}-2$ hybrids. The experiment presented in Table 4 was the second of six experiments sequentially performed within a 2-year period in which the proportion of continuously propagated $\mathrm{T}_{\text {HYB }}-2$ hybrids exhibiting IL-1 re-

TABLE 3

Differential Mitogen Sensitivity of $T_{H Y B}-1$ and $T_{H Y B}-2$ Hybrids

\begin{tabular}{lrrr}
\hline & $\begin{array}{c}\text { Percent maximal IL-2 production by PMA + ionomycin-stimulated } \\
\text { hybrids (OD from hybrids cultured with SPL + GPMBP) }\end{array}$ \\
\cline { 2 - 3 } $\begin{array}{c}\text { Hybrid (and subset) } \\
\text { designation }\end{array}$ & Experiment \#1 & Experiment \#2 & Experiment \#3 \\
\hline LSS-A1 (1) & $73 \%(0.658)$ & $93 \%(0.673)$ & $90 \%(0.844)$ \\
LSS-D1 (1) & $81 \%(0.682)$ & $85 \%(0.711)$ & $102 \%(0.730)$ \\
LSP-A1 (2) & $5 \%(0.527)$ & $18 \%(0.633)$ & $32 \%(0.505)$ \\
LSP-A2 (2) & $6 \%(0.704)$ & $21 \%(0.658)$ & $21 \%(0.679)$ \\
LAS-A1 (2) & $12 \%(0.447)$ & $26 \%(0.557)$ & $24 \%(0.576)$ \\
LSS-B2 (2) & $5 \%(0.619)$ & $24 \%(0.720)$ & $16 \%(0.849)$ \\
LSS-C1 (2) & $7 \%(0.455)$ & $16 \%(0.456)$ & $43 \%(0.460)$ \\
LSS-C2 (2) & $10 \%(0.503)$ & $12 \%(0.622)$ & $21 \%(0.630)$ \\
\hline
\end{tabular}

${ }^{a} \mathrm{~T}$ cell hybrids $\left(2.5 \times 10^{4} /\right.$ well $)$ were cultured either with $5 \times 10^{5} \mathrm{SPL} /$ well and $1 \mu M$ GPMBP or with $2 \mu M$ ionomycin and $60 \mathrm{nM}$ PMA. Supernatants were then tested for IL-2 content by the MTT assay of CTLL viability. Percent maximal IL-2 production was defined as mean OD values from triplicate wells with $60 \mathrm{n} M$ PM $\Lambda+2 \mu M$ ionomycin divided by the mean OD values from triplicate wells with $2 \mu M$ GPMBP + SPI. 

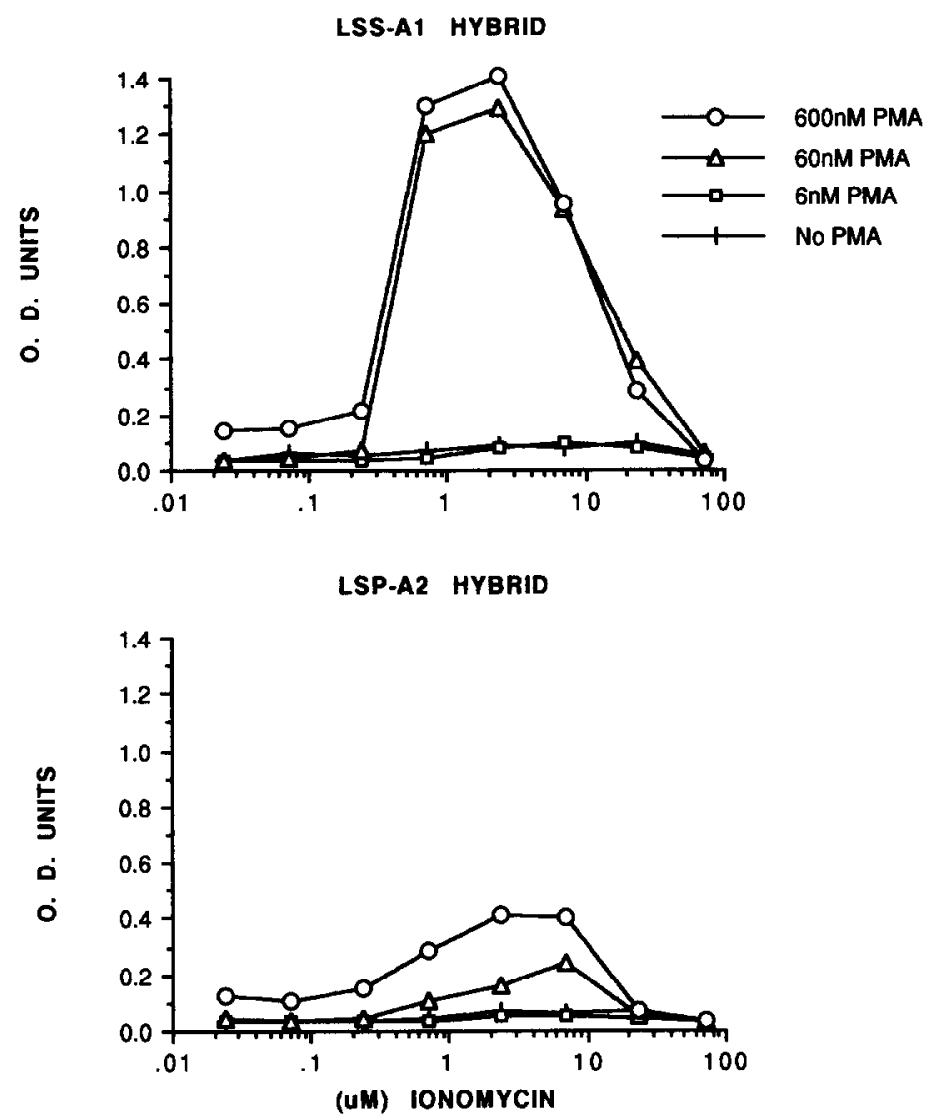

FIG. 8. T hybrid subsets can also be distinguished by differences in mitogenic responsiveness to PMA and ionomycin. T cell hybrids or BW5147 cells $\left(2.5 \times 10^{4} /\right.$ well) were cultured with designated concentrations of ionomycin and PMA for $24 \mathrm{hr}$. IL-2 production was assayed by the MTT assay of CTLL growth. LSS$\mathrm{A} 1$ and LSP-A2 are $\mathrm{T}_{\mathrm{HYB}}-1$ and $\mathrm{T}_{\mathrm{HYB}}-2$ hybrids, respectively.

sponsiveness was $2 / 2,6 / 7,2 / 8,0 / 8,0 / 8$, and $0 / 3$, respectively. These hybrids nevertheless continued to exhibit full responsiveness to GPMBP in the presence of normal SPL, indicating that these hybrids retained full reactivity to co-stimulation by RSNAdh SPL. It is not known whether chromosomal loss or other unknown variables accounted for this apparent loss of IL-1 reactivity.

These results suggest that IL-1 and RS-NAdh SPL may provide separate but functionally related co-stimulatory signals. Even though IL-1 and the cell-associated costimuli represent distinct signals, it is possible that both may act on MBP-specific $T$ cells to fulfill the same co-stimulatory requirement. One possibility is that the two different co-stimulators may act to augment $T$ cell responses in different anatomical locations or during different phases of the immune response. For example, RS-NAdh accessory cells may be the primary physiological mediators of this co-stimulatory activity in lymphoid organs whereas IL-1 may fulfill this requirement in sites of inflammation.

Subsets of T-helper cells in EAE. Although the role of radiosensitive co-stimuli in EAE induction has yet to be defined, three observations suggest a close relationship 
TABLE 4

IL-1 Partially Reconstitutes Responses of Newly Derived $\mathrm{T}_{\mathrm{HYB}}-2$ Hybrids

\begin{tabular}{|c|c|c|c|c|}
\hline \multirow[b]{2}{*}{$\begin{array}{l}\text { Hybrid designation } \\
\text { (and subset) }\end{array}$} & \multicolumn{3}{|c|}{$\begin{array}{l}\text { cpm }\left(\times 10^{-3}\right) \text { of }\left[{ }^{3} \mathrm{H}\right] \text { thymidine incorporation by } \\
\text { CTLLs as a measure of IL-2 production by hybrids } \\
\text { cultured with irradiated thymocytes and }{ }^{a}\end{array}$} & \multirow[b]{2}{*}{$\begin{array}{c}\text { Percent maximal increase } \\
\text { due to IL } 1\end{array}$} \\
\hline & GPMBP & $\begin{array}{l}\text { GPMBP }+10 \mathrm{U} \\
\mathrm{IL} 1 / \mathrm{ml}\end{array}$ & $\begin{array}{l}\text { GPMBP }+100 \mathrm{U} \\
\text { ILl } 1 / \mathrm{ml}\end{array}$ & \\
\hline LSS-A1 (1) & 88 & 93 & 96 & 10 \\
\hline LSS-D1 (1) & 98 & 102 & 97 & 4 \\
\hline LSS-D2 (1) & 71 & 91 & 89 & 27 \\
\hline LSS-D3 (1) & 83 & 94 & 90 & 13 \\
\hline LAS-AI (2) & 15 & 28 & 27 & 79 \\
\hline LSP-A1 (2) & 16 & 85 & 88 & 454 \\
\hline LSP-A2 (2) & 20 & 46 & 45 & 130 \\
\hline LSS-B3 (2) & 16 & 33 & 23 & 103 \\
\hline LSS-B4 (2) & 5 & 28 & 35 & 595 \\
\hline LSS-C1 (2) & 16 & 34 & 40 & 155 \\
\hline LSS-C2 (2) & 12 & 9 & 11 & -4 \\
\hline
\end{tabular}

${ }^{a} \mathrm{~T}$ cell hybrids $\left(5 \times 10^{5} /\right.$ well $)$ and irradiated thymocytes $\left(1500 \mathrm{rads}, 5 \times 10^{5} /\right.$ well) were cultured for 24 hr with or without GPMBP in the presence or absence of recombinant human IL-1 $\beta$ (Immunex Corp., Seattle). Supernatants were then tested for IL-2 content by measuring proliferation of CTLLs.

of the co-stimulus-dependent $\mathrm{T}_{\mathrm{HYB}}-2$ subset with EAE-inducing $\mathrm{T}$ cells. First, MBPsensitized lymph node cells with specificity for the synthetic peptides $\left[\mathrm{P}^{80}\right] \mathrm{GP68}-84$ and $\left[\mathrm{A}^{75}\right] \mathrm{GP} 68-84$ expressed potent EAE transfer activity even though T cells of this specificity were not detected by in vitro proliferative assays (8). This finding indicated that these $T$ cell clonotypes expressed encephalitogenic activity rather than proliferative activity at this phase of the immune response. Three of twelve hybrids also exhibited specificity for either the $\left[\mathrm{A}^{75}\right] \mathrm{GP} 68-84$ peptide (LAS-A1 hybrid) or the $\left[\mathrm{P}^{80}\right] \mathrm{GP68}-84$ peptide (LSP-A1 and LSP-A2 hybrids). Notably, all three of these hybrids were of the $\mathrm{T}_{\mathrm{HYB}}-2$ subset. Together, these studies support the concept that the normal counterparts of at least some co-stimulus-dependent $\mathrm{T}_{\mathrm{HYB}}-2$ hybrids have EAE-inducing activity.

Second, previous studies have shown that continuously propagated lines of encephalitogenic $\mathrm{T}$ cells have attributes similar to that of $\mathrm{T}_{\mathrm{HYB}^{-}}-2$ hybrids. For example, Ben-Nun and Cohen derived a T cell line that responded to MBP in the presence of nonfractionated lymphoid cells (5). However, the same $\mathrm{T}$ cells did not respond to MBP when cultured with the corresponding adherent cell fraction of accessory cells. The lack of accessory cell activity by adherent cells had to be reconciled with the knowledge that these cells are primarily macrophages active in antigen presentation. Like $\mathrm{T}_{\mathrm{HYB}}-2$ hybrids, nonadherent accessory cells were apparently required in addition to the adherent APCs to support activation of this MBP-specific T cell line. Hence, these findings are consistent with the possibility that nonadherent accessory cells may provide the same requisite co-stimuli to encephalitogenic $T$ cells as they do for $T_{\mathrm{HYB}}$ 2 hybrids.

Third, both encephalitogenic $\mathrm{T}$ cells and newly derived $\mathrm{T}_{\mathrm{HYB}^{-}}-2$ hybrids were responsive to exogenous IL-1 (14) (Table 4). For example, previous research has revealed that IL-1 acts synergistically with MBP to activate expression of EAE transfer activity 
by MBP-sensitized lymph node cells. In contrast, IL-1 was less active in promoting in vitro proliferative responses to $\mathrm{MBP}$ in parallel cultures. These findings suggest that two distinct subsets of MBP-specific $T$ cells can be defined by differential responsiveness to IL-1. This IL-1 responsive subset may correspond to the $\mathrm{T}_{\mathrm{HYB}}-2$ subset because newly derived $\mathrm{T}_{\mathrm{HYB}}-2$ hybrids were also responsive to IL-1 as measured by MBPstimulated lymphokine production (Table 4).

Rather than representing divergent lineages, the $T_{\mathrm{HYB}^{-}} 1$ and $T_{\mathrm{HYB}}-2$ subsets may represent sequential phases of a given differentiation pathway. Repeated exposure to certain types of antigens during immune responses may promote differentiation of antigen-specific $T$ cells such that they acquire novel co-stimulatory requirements along with specialized effector functions. If true, then the $T_{\mathrm{FYB}}-2$ subset may represent differentiated effector $T$ cells that require "help" for clonal expansion and co-stimulation for activation of effector functions. Co-expression of stringent co-stimulatory requirements with specialized effector activities may provide a means for immune regulation of those effector activities.

These observations may provide insight into why it has been so difficult to identify $T$ cell antigens that cause spontaneous autoimmune disease in experimental animals and in humans. This mystery stems from the difficulty in reliably detecting in vitro proliferative responses to predicted autoantigens by $\mathrm{T}$ cells directly isolated from target organs. As exemplified by patients with multiple sclerosis, $T$ cells that are directly isolated from blood, from cerebrospinal fluid, or from demyelinating plaques do not appear sensitized to CNS antigens as measured by proliferative assays $(34,35)$. In fact, the proportion of myelin-specific $\mathrm{T}$ cell lines isolated from the peripheral blood of multiple sclerosis patients appears similar to their frequency in control individuals $(36,37)$. These findings stand in contrast to other experimental approaches which have suggestcd that disease-specific $\mathrm{T}$ cell sensitization to myelin antigens does occur in multiple sclerosis $(38,39)$. Even in experimentally induced models of autoimmunity, the $T$ cell clonotypes most closely associated with induction of disease appear to lack autocrine proliferative activity $(7,8,10-13)$. In fact, the lack of detectable $T$ cell proliferative responses against CNS-specific antigens in multiple sclerosis may be mechanistically related to lack of MBP-specific proliferation by rat $\mathrm{T}$ cells responsible for the adoptive transfer of $\operatorname{EAE}(7,8)$.

This possibility is supported by the observation that target organs affected in different autoimmune diseases such as the cerebrospinal fluid of patients with multiple sclerosis, the synovial fluid of patients with rheumatoid arthritis, or peripheral blood of patients with systemic lupus erythematosis are populated by $T$ cells lacking normal responsiveness to mitogens (40-43). In a similar manner, an encephalitogenic line of rat $\mathrm{T}$ helper cells also was refractory to stimulation with the mitogen Con $\mathrm{A}$ even when these cells were cultured with splenic macrophages (5). In both cases, mitogenic unresponsiveness appears to be due to the lack of appropriate co-stimuli. That is, the mitogenic activity of $\mathrm{T}$ cells isolated from multiple sclerosis patients was restored with PMA (43), and optimal mitogenic responses by the encephalitogenic rat $T$ cell line were observed only in the presence of nonfractionated SPL (5). In a similar manner, the lack of responsiveness of $\mathrm{T}_{\mathrm{HYB}}-2$ hybrids to PMA and ionomycin may be associated with their requirement for co-stimulatory molecules on RS-NAdh SPL.

Likewise, differentiation pathways of autoreactive $T$ cells in multiple sclerosis may link upregulation of effector cell activity with downregulation of IL-2-dependent autocrine proliferation. Accordingly, organs affected in multiple sclerosis and rheumatoid 
arthritis are primarily populated by $\mathrm{T}$ cells expressing the $\mathrm{CD} 4^{+}, \mathrm{CDw} 29^{+}$"helperinducer" or "memory" phenotype (44-46). Conversely, relatively few of these cells express the $\mathrm{CD}^{+}, \mathrm{CD} 45 \mathrm{RA}^{+}$" naive or suppressor-inducer" phenotype. Fractionation of these subsets reveals that the differentiated subset rather than the naive subset is refractory to mitogenic stimulation (43). Together, these studies support the view that target organs in autoimmune disease contain sequestered populations of effector $T$ cells which have differentiated such that their expression of effector activity is coupled with the expression of stringent requirements for co-stimulation.

\section{ACKNOWLEDGMENTS}

The authors thank Dr. David W. Thomas for insightful discussions and Mr. Andy Bruce for skilled technical assistance. The authors also thank Drs. Sandra Armstrong, James McCubrey, Mason Smith, and Yoji Shimizu for careful critiquing of this manuscript.

\section{REFERENCES}

1. Paterson, P. Y., and Swanborg, R. H., In "Immunological Diseases" (M. Samter, D. J. Talmage, M. M. Frank, K. F. Austen, and H. N. Claman, Eds.), pp. 1877-1916. Little, Brown, Boston, 1988.

2. Chou, C.-H. J., Chou, F. C.-H., Kowalski, T. J., Shapira, R., and Kibler, R. F., J. Neurochem. 28, 115 , 1977.

3. Martenson, R. E., Nomura, K., Levine, S., and Sowinski, R., J. Immunol. 118, 1280, 1977.

4. Chou, C.-H. J., Fritz, R. B., Chou, F. C.-H., and Kibler, R. F., J. Immunol. 123, $1540,1979$.

5. Ben-Nun, A., and Cohen, I. R., J. Immunol. 129, 303, 1982.

6. Beraud, E., Reshef, T., Vandenbark, A. A., Offner, H., Fritz, R., Chou, C.-H. J., Bernard, D., and Cohen, I. R., J. Immunol. 136, 511, 1986.

7. Mannie, M. D., Paterson, P. Y., U'Prichard, D. C., and Flouret, G., Proc. Natl. Acad. Sci. USA 82, $5515,1985$.

8. Mannie, M. D., Paterson, P. Y., U'Prichard, D. C., and Flouret, G., J. Immunol. 142, 2608, 1989.

9. Mannie, M. D., Paterson, P. Y., U'Prichard, D. C., and Flouret, G., J. Neuroimmunol. 26, 201, 1990.

10. Fox, G. M., Redmond, T. M., Wiggert, B., Kuwabara, T., Chader, G. J., and Gery, I., J. Immunol. 138, $3242,1987$.

11. Kotake, S., Wiggert, B., Zhang, X.-Y., Redmond, T. M., Chader, G. J., and Gery, I., J. Immunol. 145, 534, 1990.

12. Gregerson, D. S., Fling, S. P., Obritsch, W. F., Merryman, C. F., and Donoso, L. A., Cell. Immunol. 123, 427, 1989.

13. Merryman, C. F., Smith, N., and Donoso, L. A., Curr. Eye Res. 9, 97, 1990.

14. Mannie, M. D., Dinarello, C. A., and Paterson, P. Y., J. Immunol. 138, 4229, 1987.

15. Mannie, M. D., Paterson, P. Y., Thomas, D. W., and Nairn, R., J. Immunol. 144, 440, 1990.

16. Mueller, D. L., Jenkins, M. K., and Schwartz, R. H., Annu. Rev. Immunol. 7, 445, 1989.

17. Weaver, C. T. and Unanue, E. R., Immunol. Today 11, 49, 1990.

18. Kurt-Jones, E. A., Hamberg, S., Ohara, J., Paul, W. E., and Abbas, A. K., 1987. J. Exp. Med. 166, $1774,1987$.

19. Greenbaum, L. A., Horowitz, J. B., Woods, A., Pasqualini, T., Reich, E.-P., and Bottomly, K., J. Immunol. 140, 1555, 1988.

20. Fernandez-Botran, R., Sanders, V. M., Mosmann, T. R., and Vitetta, E. S., J. Exp. Med. 168, 543, 1988.

21. Lichtman, A. H., Chin, J., Schmidt, J. A., and Abbas, A. K., Proc. Natl. Acad. Sci. USA 85, 9699, 1988.

22. Jenkins, M. K., Pardoll, D. M., Mizuguchi, J., Chused, T. M., and Schwartz, R. H., Proc. Natl. Acad. Sci. USA 84, 5409, 1987.

23. Ashwell, J. D., Cunningham, R. E., Noguchi, P. D., and Hernandez, D., J. Exp. Med. 165, $173,1987$.

24. Mercep, M., Noguchi, P. D., and Ashwell, J. D., J. Immunol. 142, 4085, 1989.

25. Swanborg, R. H., Swierkosz, J. E., and Saieg, R. G., J. Immunol. 112, 594, 1974.

26. McMaster, W. R., and Williams, A. F., Eur. J. Immunol. 9, 426, 1979.

27. Mannic, M. D., Paterson, P. Y., U'Prichard, D. C., and Thomas, D. W., Cell. Immunol. 122, 534, 1989.

28. Mosmann, T., J. Immunol. Methods 65, 55, 1983. 
29. Buus, S., Sette, A., and Grey, H. M., Immunol. Rev. 98, 115, 1987.

30. Weiss, A., Imboden, J., Shoback, D., and Stobo, J., Proc. Natl. Acad. Sci. USA 81, 4169, 1984.

31. Hagiwara, H., Yokota, T., Luh, J., Lee, F., Arai, K.-I., Arai, N., and Zlotnik, A., J. Immunol. 140, $1561,1988$.

32. Quill, H., and Schwartz, R. H., J. Immunol. 138, 3704, 1987.

33. Lorenz, R. G., and Allen, P. M., Nature 340, 557, 1989.

34. Hughes, R. A. C., Gray, I. A., Gregson, N. A., and Metcalfe, R. A., Acta Neurol. Scand. 65, 161, 1982.

35. Hafler, D. A., Benjamin, D. S., Burks, J., and Weiner, H. L., J. Immunol. 139, 68, 1987.

36. Burns, J., Rosenzweig, A., Zweiman, B., and Lisak, R. P., Cell. Immunol. 81, 435, 1983.

37. Pette, M., Fujita, K., Kitze, B., Whitaker, J. N., Albert, E., Kappos, L., and Wekerle, H., Neurology 40, $1770,1990$.

38. Allegretta, M., Nicklas, J. A., Sriram, S., and Albertini, R. J., Science 247, 718, 1990.

39. Olsson, T., Zhi, W. W., Hojeberg, B., Kostulas, V., Yu-Ping, J., Anderson, G., Ekre, H.-P., and Link, H., J. Clin. Invest. 86, 981, 1990.

40. Kam-Hansen, S., I ink, H., Fryden, A., and Moller, E., Scand. J. Immunol. 10, 161, 1979.

41. Miyasaka, N., Nakamura, T., Russell, I. J., and Talal, N., Clin. Immunol. Immunopathol. 31, 109, 1984.

42. Linker-Israeli, M., Bakke, A. C., Kitridou, R. C., Gendler, S., Gillis, S., and Horwitz, D. A., J. Immunol. 130, 2651, 1983.

43. Chofflon, M., Gonzalez, V., Weiner, H. L., and Hafler, D. A., Eur. J. Immunol. 19, 1791, 1989.

44. Chofflon, M., Weiner, H. L., Morimoto, C., and Hafler, D. A., Ann. Neurol. 25, 494, 1989.

45. Morimoto, C., Romain, P. L., Fox, D. A., Anderson, P., DiMaggio, M., Levine, H., and Schlossman, S. F., Am. J. Med. 84, 817, 1988.

46. Corrigan, E., Hutchinson, M., and Feighery, C., Acta Neurol. Scand. 81, 443, 1990. 